Nunt. Antiquus, Belo Horizonte, v. 15, n. 1, p. 61-76, 2019

\title{
Sobre Polímnia e suas irmãs
}

\section{On Polymnia and her sisters}

\author{
Ioannis Petropoulos \\ Democritus University of Thrace, Thrace / Grécia \\ Center for Hellenic Studies, Harvard University, Nafplio / Grécia \\ yiannis@chs.harvard.edu
}

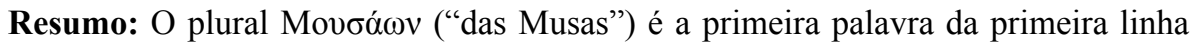
da Teogonia de Hesíodo, um poema sobre as origens do mundo e dos deuses - e o começo de Hesíodo como um poeta ensinado e "inspirado" pelas Musas. A partir de várias análises e abordagens, tanto antigas quanto recentes, esse artigo oferece uma reflexão sobre as Musas como agentes intelectuais na iniciativa de compor e apresentar poesia em performance. O tratamento de Platão da inspiração é contrastado com o de Hesíodo; as Musas no Ion servem de fonte para o criticismo do filósofo da mímesis com a sua enárgeia característica. A admissão de Hesíodo que cantores e poetas podem ser enganados pelas Musas é um indicativo da originalidade intelectual Grega, como é o conceito tradicional das Musas.

Palavras-chave: Musas; Polímnia; inspiração; poesia; Hesíodo; Homero; enárgeia.

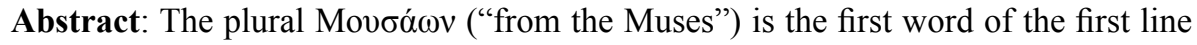
of Hesiod's Theogony, a poem about the origins of the world and of the gods - and Hesiod's first step as a poet taught and "inspired" by the Muses. Starting from various analyses and approaches both ancient and recent, this article is a reflection on the Muses as intellectual agents in the enterprise of composing and performing poetry. Plato's treatment of inspiration is contrasted to Hesiod's: the Muses in his work Ion are sources for the philosopher's criticism of the mimesis with its trademark enárgeia. Hesiod's admission that singers and poets can be misled by the Muses is an index of Greek intellectual originality, as is the traditional concept of the Muses

Keywords: Muses; Polymnia; inspiration; poetry; Hesiod; Homer; enárgeia. 
Todo museu no mundo é um espaço sagrado, um santuário dedicado às Musas. Este é o sentido original da palavra 'museu'

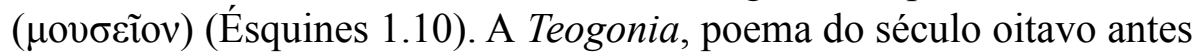
de Cristo, atribuído a Hesíodo, ${ }^{1}$ talvez já assuma que santuários para as Musas existiram naquele tempo. A Teogonia apresenta o primeiro e mais completo retrato das Musas na história da literatura. Movøó $\omega v$

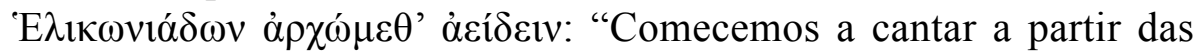
Musas do Monte Hélicon", é o primeiro verso do poema. A composição de Hesíodo pode ser vista como equivalente ao livro do Gênesis. Com seus mais de 1.000 versos narrando a criação do cosmos a partir do vácuo (Xáoç/Chaos) e a incoerência e violência dos monstros. ${ }^{2}$ A primeira palavra no poema é 'Musas': o nome, derivado da raiz do Indo-europeu *men-, "pensar, se engajar em atividade mental", significa, literalmente, "Mentalizadores(as), agentes do pensamento" (NAGY, 1990, p. 59-60, nota 38). Sem essas divindades do pensamento, música, dança e todas as belas artes não seriam possíveis.

De acordo com Hesíodo, monstros como aqueles que descendem de Fórcis e Ceto (Teogonia 270-336) existiam mesmo antes do nascimento das Musas. Zeus teve de superar o monstro por excelência, Tifeu, antes de ascender ao trono como principal divindade dos gregos e estabelecer a ordem cósmica (Teogonia 820-885). É impressionante que Zeus tenha triunfado sobre Tifeu com as armas providas por outros monstros, os três Ciclopes (Teogonia 139-141). Depois de vários casamentos, ele se casou com Mnemosyne, ou 'Memória', uma Titã e um tipo de monstro. ${ }^{3}$ Ele dormiu com "Memória" de "belos cabelos" em nove noites sucessivas e criou as nove Musas (Teogonia 915 ss.), cada uma diferenciada por um nome alegórico, refletindo sua particular esfera de influência. Se Zeus não

\footnotetext{
${ }^{1}$ Hesíodo, Homero e todos os outros textos clássicos são citados segundo as edições da Oxford.

${ }^{2} \mathrm{O}$ poema narra começos, diferentemente dos épicos homéricos que narram eventos in medias res. A Teogonia não é uma narrativa linear, mas antes um catálogo genealógico que contém estruturas em anel, anacronias e genealogias que debilitam a sua narrativa cronológica; cf. Rengakos (2009), especialmente as páginas 205-212.

${ }^{3}$ Os temíveis Titãs, na medida em que são os irmãos dos três Ciclopes (Teogonia 139-46) e os Centimanos (Teogonia 147-53), também deve se presumir que sejam monstruosos.
} 
tivesse derrotado Tifeu, não haveria Justiça, nem Musas, nem discurso construído socialmente, nem música, nem dança, nem literatura, nem educação. De fato, nem Teogonia! Que mundo tenebroso, feio seria este!

Essas deusas residem no Olimpo, mas algumas vezes habitam a natureza bruta, o espaço selvagem: montanhas, cachoeiras, fontes, espaços abertos em geral. Elas podem, originariamente, ter sido deusas sedutoras dessa natureza bruta, selvagem; ${ }^{4}$ não é acidental que Hesíodo as encontre no pé da montanha (Teogonia 23) e mencione dois riachos (Teogonia 5-6) e as fontes (Teogonia 3,6) que elas habitam, nem que Aristófanes (Rãs 229-230) as associe a Pã, o hiper-sexualizado deus dos pastores e rebanhos que toca flauta. Hesíodo ou impôs um sentido às Musas ou herdou tal sentido já imposto, com os pés ao mesmo tempo fortes e macios, e a pele suave e virginal - como ele as descreve (Teogonia $3,5,8)$. Mas elas nunca deixam desaparecer sua potencialidade mais sombria, pois elas fornecem informações não apenas sobre o presente e o passado, mas também sobre o futuro (Teogonia 32,38$).{ }^{5}$ Que a poesia e profecia estão interconectadas, é atestado amplamente em muitas culturas na história. ${ }^{6}$ Oniscientes, as Musas dão uma outra perspectiva para os mortais.

${ }^{4}$ Cf. LIMC..., 1992, VII, s.v.v. "Mousa, Mousai", p. 658; cf. também CANCIK; SCHNEIDER, 2006, s.v. "Muses", p. 323-324.

${ }^{5}$ Hesíodo, de fato, se apresenta (Teogonia 32) como um tipo de Calcas cantante (Iliad 1.70). Nos Trabalhos e os Dias (661-662), o poeta promete contar "a mente de Zeus", ou seja, suas intenções ou planos, em relação à navegação, uma atividade da qual ele

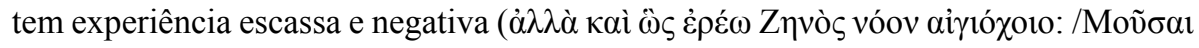

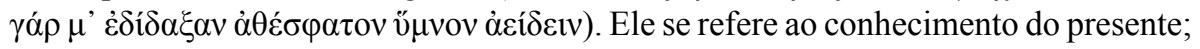
mas "a mente de Zeus" também pode abarcar conhecimento revelado do futuro. West (1978, p. 322 ad loc). deixa aberta a possibilidade de que Hesíodo afirma ser capaz de prever as condições meteorológicas ou do "modo como o mundo funciona em geral". ${ }^{6} \mathrm{O}$ poeta-profeta é menos comum na tradição grega; cf. West, (1966, p. 166) sobre a Teogonia (32); Chadwick (1942), citado por West, defende que poetas-adivinhos na tradição oral grega como em outras culturas tinham acesso à informação sobre o passado e o futuro. O tema do poeta como profeta ocorre em Pi. fr. 150, Pae. 6.6; Bacch. 9.3, citado com bibliografia por P. Murray (1996, p. 118) sobre Platão, Ion (534b 7); também Dodds (1951, p. 82). 


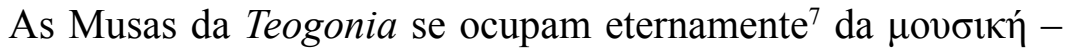
abreviação de $\mu$ ovбikń $\tau \dot{\varepsilon} \chi v \eta$ - (de onde vem "música" em português) que aqui inclui canção (na forma de hinos tanto aos deuses mais obscuros pré-olímpicos quanto aos Olímpios) e dança: de um lado, lógos com o seu rhythmós inerente e, do outro, movimento medido. Inicialmente Hesíodo descreve estas virgens dançando no pico do Monte Hélicon (na Grécia central) no escuro da noite da seguinte maneira: "na encosta mais alta do Hélicon elas dançam belamente, despertando o desejo" (Teogonia 7-8). ${ }^{9}$

Depois de terem se banhado (Teogonia 5), elas sempre dançam belamente - e se eu posso ousar dizer - de maneira sexy, erótica (cf.

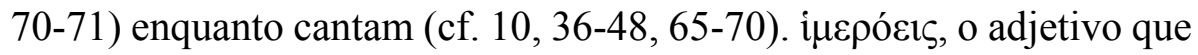
o poeta usa acima para descrever sua dança sugere hímeros, o tipo de desejo físico indomável que Páris sentiu quando ele viu Helena pela primeira vez (cf. Ilíada 3.446). Na sua casa no Olimpo, o deus do Desejo Himeros, junto com as Khárites ("Graças", filhas de Zeus e a Oceanida Eurínome), as observa dançando (Teogonia 64). Há um toque de perigo erótico na dança; as Musas do Hélicon são, afinal de contas, ninfas locais e seu banho sensual (cf. Teogonia 5, "pele macia"), dança e canto em uma locação remota sugerem a possibilidade de ninfolepsia; na escuridão elas podem seduzir o poeta, uma vez que ele está tomado pela sua beleza, voz e movimento. ${ }^{10}$ Mas as Musas na sua versão Olímpia são também filhas

\footnotetext{
${ }^{7}$ A partir de Bakker (2005), especialmente o capítulo 8, eu noto que as Musas vão cantar eternamente enquanto o hino de Hesíodo for apresentado eternamente e o performer perceber, a cada ocasião, as Musas dançando no presente. Como Bakker (2005, grifo do autor) declara em outra conexão, "[s]e algo é repetido, é a performance da cena, não a cena ela mesma".

${ }^{8} \dot{\varepsilon} v \varepsilon \pi$ oí $\sigma \alpha v \tau$ o é um aoristo gnômico de acordo com a leitura padrão (ROWE, 1978, p. 41 ad loc.); ou como West (1966, p. 155) nota, é "atemporal”. Mas Bakker (2005), também no capítulo 8, mostra o seguinte na poesia épica e nos hinos, e.g. o Hino homérico a Apolo 1-13: "agora nós podemos ver o tempo do presente não como genérico ou histórico, mas como perceptual. E os aoristos não são nem gnômicos nem uma anomalia narrativa, mas perceptuais também [...]".

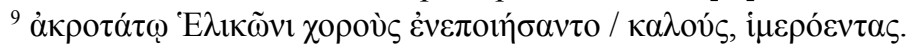

${ }^{10}$ Cf. Pache (2010, p. 25-26): "[...] o começo do poema contém vários elementos de encontros ninfoléticos... se banhar, dançar e cantar todos evocam encontros eróticos." Mas Pache postula que Hesíodo aqui reverte o padrão "Macho seduz fêmea"; eu sugiro
} 
de Zeus e mantêm a sua ordem: elas mantêm o seu reinado cantando o seu triunfo sobre Cronos e sua ascensão ao reino (Teogonia 47-49; cf. 70-74). ${ }^{11}$ A dança delas é algo ordenado, e quando os seres humanos as imitam, eles estão defendendo a beleza e a ordem desse mundo imperfeito.

O número de Musas variou através da Antiguidade. Foi Hesíodo que as definiu e caracterizou. ${ }^{12}$ Estudiosos do período helenístico e poetas as (re)definiram posteriormente. ${ }^{13}$ Mas é bom lembrar que a nomenclatura de Hesíodo é, de fato, uma tentativa de atribuir nomes a um conjunto unificado de fenômenos da criatividade e performance humanas. As Musas dotam o poeta com genialidade ou habilidade permanente; sua inspiração tem a forma de uma assistência temporária, implorada pelo poeta. Ele, no entanto, tem um papel consciente e autônomo na composição através da técnica - "produção" ( sua "criatividade". Na medida em que a composição é simultânea com a performance, as deusas ajudam o cantor-poeta a atingir a articulação

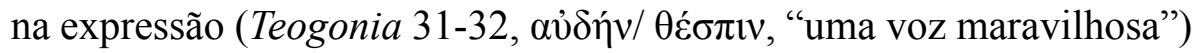
e fluência na entrega (Teogonia 39-40, 96-97, etc.). ${ }^{14}$ Como filhas de Mnemosýne ("Memória"), elas despertam a memória do cantor para temas e fórmulas, ${ }^{15}$ presumivelmente não menos do que elas excitam a memória física da coreografia do dançarino. A inspiração por trás da criação e performance envolve uma relação religiosa, mas também profundamente

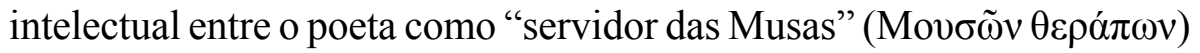

que o padrão fundamentando a passagem é "deusa local feminina seduz macho". Este é o padrão costumeiro nos contos gregos modernos das Nereides.

${ }^{11}$ West (1966, p. 172-173) acertadamente rejeita a linha 48 principalmente porque ela não escande sob nenhuma regra.

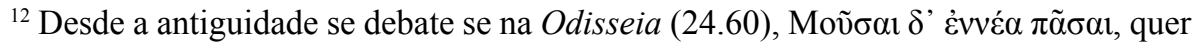
dizer "todas nove Musas" ou "Musas, nove ao todo".

${ }^{13}$ As Musas, já intelectualizadas em Homero e Hesíodo, são ainda mais intelectualizadas em Calímaco (e.g. Aetia 1-2, fr 2) e Apolônio de Rodes, e a relação entre as Musas e o poeta se torna uma de colaboração acadêmica, inocente da solenidade épica ou hesiódica.Cf. Hutchinson (1988, p. 43-44).

${ }^{14}$ Cf. Murray (1981, p. 94-95) sobre as Musas e a performance.

${ }^{15}$ Cf. Murray (1981, p. 94) sobre as Musas e a memória na composição oral. Ver também sobre $\mu \mu v \eta ́ \sigma \kappa \varepsilon \sigma \theta \alpha$ abaixo. 
e suas benfeitoras divinas. ${ }^{16}$ As Musas são plurais porque a criatividade, produto de uma ação mental, tem muitas facetas. De muitos modos as Musas são análogas entre si: por exemplo, os nomes Eutérpe/"Agrado" e Terpsikhóre/"Agrado-dançante", ou "Agrado do coral", sugerem o "prazer de testemunhar as Musas" dançando e cantando em coro/coral (khorós), isto é, um grupo de dançarinos/as e cantores/as (na Grécia antiga, a tradição coral e a dança estavam interconectadas). Esses nomes também indicam o prazer produzido por um cantor mortal ou coro. Kalliópe/"Bela voz" e Melpoméne/"Cantora" são noções intimamente ligadas. A maioria dos nomes foi cunhada a partir de frases no hýmnos. ${ }^{17}$

O retrato das Musas que Hesíodo pinta é verbal; é um exemplo do que os antigos filósofos e literatos chamavam de enárgeia (ou, alternativamente, phantasía), quer dizer, vivacidade de apresentação, especialmente da visão poética. ${ }^{18}$ Os primeiros 115 versos da Teogonia compõem dois hinos, ou melhor, um hino às Musas em duas partes: um dedicado às Musas do Hélicon (1-35), o outro às Musas olímpicas (36-115), suas correlatas (RENGAKOS, 2009, p. 205-206). Um hino,

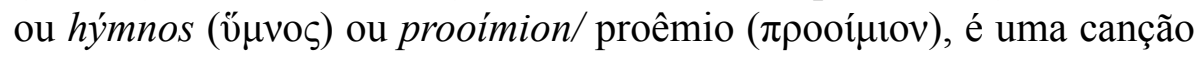
narrativa em louvor à divindade. $\mathrm{O}$ nome prooímion é relacionado, etimologicamente, ao verbo Indo-Europeu para "costurar", enquanto o

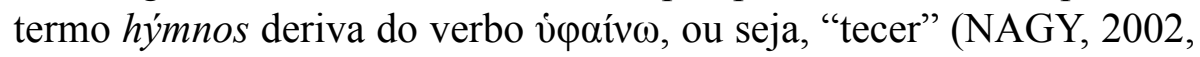
p. 70-98). ${ }^{19}$ Uma canção é um tecido figurativo criado por um cantor apresentando-se sob a inspiração das Musas (falarei sobre a inspiração em breve). Costura, tecelagem e tecidos são parte da ideologia grega da canção (ou música). ${ }^{20}$

A abertura da Teogonia é um hino para as Musas que, por outro lado, estão cantando um hino a Zeus e a outros deuses, incluindo aqueles da geração primordial, Cronos, Sol, Lua, Oceano e Noite. Este hino toma

\footnotetext{
${ }^{16}$ Cf. Murray (1981, p. 94-97).

${ }^{17}$ Nessa acepção, cf. Rowe (1978, p. 46) com relação a Teogonia, 77-79.

${ }_{18}$ Para a enárgeia como uma forma de dê̂xis particularmente nos hinos homéricos, cf. Bakker (2005, p. 157); para uma abordagem cognitiva da enárgeia homérica, cf. Grethlein e Huitink (2017, p. 67-91).

${ }^{19}$ Especialmente a página 71 sobre a etimologia de $\mathbf{u} \boldsymbol{\mu v o s}$.

${ }^{20} \mathrm{Cf}$. a referência anterior a Nagy.
} 
cerca dos 35 versos iniciais do poema e é a primeira parte do hino maior. É uma sinfonia de combinação de vogais. Hesíodo evoca a música verbal para conjurar a beleza do coro das Musas. Essas cantoras bailarinas etéreas, envolvidas na neblina (Teogonia 9), ou seja, invisíveis, ${ }^{21}$ descem

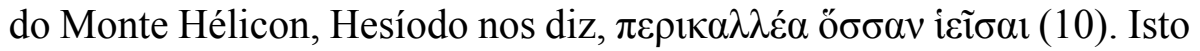
é, elas "emitem uma voz divina de beleza suprema" quando cantam em uníssono para louvar Zeus e os outros deuses, incluindo, na parte olímpica do hino, os heróis e os selvagens Gigantes (Teogonia 50).

Ao fazer isso elas estão repetindo - e vão repetir ad infinitum - ${ }^{22}$ o que fizeram no momento após seu nascimento, quando subiram ao Monte Olimpo e pela primeira vez "hineavam" seu pai Zeus e os outros deuses (Teogonia 70, cf. 52 ff.). As Musas cantam hinos perpétuos, e esta é a sua primeira função. A Musa que mais me interessa é Polímnia, "muito-hineada", ou, melhor (no sentido ativo), a que é "rica de hinos" (Teogonia 78). Ela condensa no seu próprio nome a música e a dança apresentada pelas Musas como um grupo. De fato, essas irmãs são um modelo de coro perfeito, cantando e dançando perfeitamente. ${ }^{23}$

Polímnia representa a ideal, eterna e recorrente performance de hinos pelas Musas: elas cantam "com uma mente" = "unânime" (Teogonia

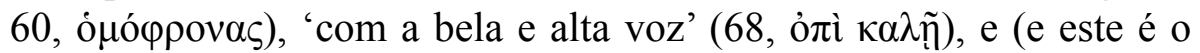
detalhe mais requintado) mesmo o som alto que vem de baixo de seus

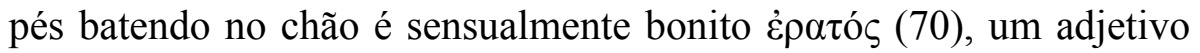

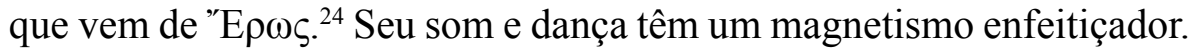
Homero muda este apelo "magnético" para as Sereias, antiMusas que cantam, mas, perversamente, não dançam (Odisséia, 12.52, passim).

\footnotetext{
${ }^{21}$ Como um narrador onisciente, Hesíodo vê as Musas.

${ }^{22}$ Cf. a nota 7 acima.

${ }^{23} \mathrm{Na}$ literatura clássica, as Musas cantam e dançam, mas sem que elas próprias façam o acompanhamento com algum instrumento. $\mathrm{Na}$ arte grega antiga, elas cantam enquanto tocam uma lira, kíthara ou aulós. Cf. LIMC..., 1992, VII. p. 658, s.v.v. "Mousa, Mousai". A caixa/cofre de Cípselo (Séc. VII a. C.?) apresenta as Musas cantando alegremente à volta de Apolo; retratadas ao meio de célebres façanhas míticas e em outros eventos, alguns deles cósmicos, este coro assume aqui um papel exemplar: PAUSÂNIAS, A Descrição de Grécia 5.17.5-5.19.10; cf. LIMC, 1992, VII, s.v.v. "Mousa, Mousai”, p. 673.

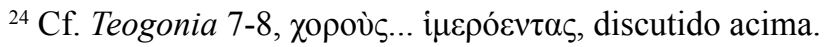


Platão, por outro lado, individualiza as Musas; no Ion a Musa é semelhante a um ímã a partir do qual Homero e seus intérpretes, os rapsodos, e seus ouvintes pendem balançando, impotentes, mas com prazer, mergulhando na irracionalidade (Ion 533d1-536d3). Quando recitando Homero em público, o rapsodo Íon diz que ele visualiza a cena épica e experimenta- $a$ virtualmente, como ele afirma: "Quando eu relato um conto de horror, meus olhos se enchem de lágrimas, e quando é de medo ou espanto, meu cabelo se arrepia de medo, e meu coração dispara" (Ion 535c1 5-7) Sócrates nota que Íon alcança isto através do estado irracional de êxtase e entusiasmo, uma forma de loucura divina (Ion 533e.5-534a; 535b 1-c 2). A audiência de Íon, também afetada pelo "magnetismo" das Musas, é transportada também, nolens volens: "Eu os vejo a partir da plataforma onde estou, eu os vejo em alguns momentos chorando e se movimentado com os olhos aturdidos para mim, e espantados com a história que narro" (Ion 535e 1-3). O rapsodo e a sua audiência estão, segundo o tratamento de Platão, fora de suas razões; ao longo do furor poeticus um performer pode atingir a enárgeia, que é uma característica da melhor mímesis no sentido próximo de imitação e performance. ${ }^{25}$ Mas se trata de uma pseudoarte, pois está afastada da contemplação da natureza das coisas e da recolecção das Formas. ${ }^{26}$ Ela põe em jogo as piores partes da alma. Nas Leis (IV. 719c 1- 719d 1) um poeta ( Musa" ${ }^{27}$ se perde na insanidade "e, como a sua arte consiste na imitação, ele está compelido a contradizer a si mesmo, frequentemente, quando ele cria personagens de temperamentos contraditórios; e ele não sabe qual desses pronunciamentos contraditórios é verdade". Ele está preso

\footnotetext{
${ }^{25}$ Platão está lançando seu criticismo irônico a todas as artes performáticas, não apenas

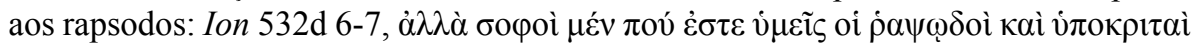

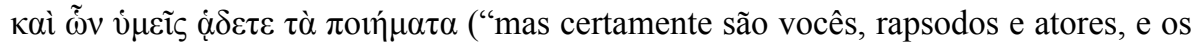
homens dos quais os poemas vocês cantam que são sábios") cf. Platão (República X. 595-607), especialmente as páginas 603-604.

${ }^{26}$ Cavarnos (1973, p. 20-22), especialmente a página 22: "No caso da pseudoarte se imita objetos inferiores, captados por um poder inferior, enquanto que no caso da arte genuína se imita objetos superiores e perfeitos captados por um poder superior nos humanos."

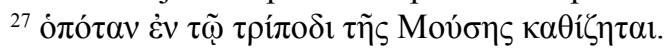


ao reino mutante da opinião ( $\delta$ ó $\xi \alpha) .{ }^{28}$ Se os deuses são bons, então as Musas não podem na sua bondade inspirar um poeta a se virar para o "seu ser mais baixo, irracional e inconsciente" (CAVARNOS, 1973, p. 22) nem fazê-lo incapaz de falar com conhecimento sequer de Homero, e ainda menos de outros poetas (Ion 532c 4-5). ${ }^{29}$ No Ion as Musas são privadas do seu papel tradicional como fontes de conhecimento. Platão, de fato, inverte a função das Musas de agentes de uma arte racional para agentes da irracionalidade. ${ }^{30}$ Portanto, suas Musas e a loucura que elas provocam não devem ser tomadas literalmente (CAVARNOS, 1973, p. 20); elas são antes meios para o criticismo do filósofo da mímesis com a sua enárgeia característica.

Eu retorno às Musas de Hesíodo: elas dançam vigorosamente, e suas vozes são incansáveis, ou melhor, "emitidas sem esforço" (Teogonia 39). ${ }^{31}$ Elas inflamam dançarinos e cantores, dando-lhes uma força física e mental formidáveis, conforme dito acima. Assim, as Musas fornecem o conteúdo e estilo da poesia. ${ }^{32}$ Elas instigam temporariamente não apenas a canção coral e a dança, mas também a canção solo. ${ }^{33}$ Demódoco, o poeta cantor cego entre os Feácios, na Odisseia, é um cantor solo que toca um instrumento de corda, a cítara - mas ele não dança. Sua cegueira está alicerçada na lenda antiga de que Homero era cego.

\footnotetext{
${ }^{28}$ Também na República (X. 598d 6-599a 4) sobre Homero e os poetas trágicos: “[...] o bom poeta deve compor com conhecimento ( $\varepsilon i \delta o ́ \tau \alpha ~ \alpha ̋ \rho \alpha ~ \pi o 1 \varepsilon i ̃ v)$, se ele vai compor sobre qualquer assunto [...] suas obras [...] estão a 'três graus afastadas' da realidade

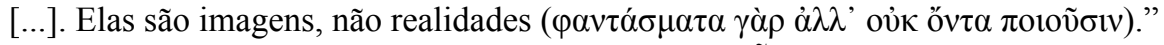

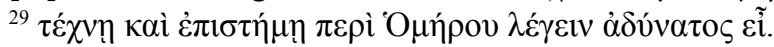

${ }^{30}$ Essa é a implicação de Murray (1981), especialmente na página 93. Platão se baseia na sua teoria da irracionalidade da inspiração pelas Musas na Dichterweihe ("iniciação em poesia”) de Hesíodo em Teogonia (22-34): Stern-Gillet (2014, p. 25-42).

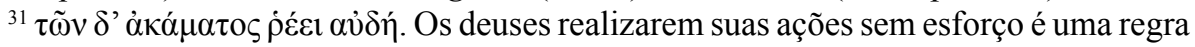
na poesia grega, religião e magia. Aqui o fluxo sem esforço da voz das Musas é análogo à fluência da performance oral, que, como nota Murray (1981, p. 95), é concomitante com a inspiração.

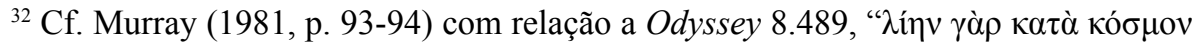

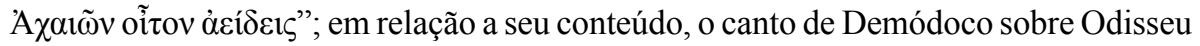
e Aquiles preserva a ordem dos eventos e os conta como aconteceram.

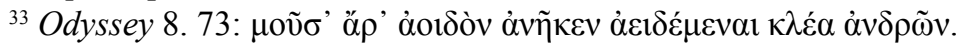


Um cantor épico como Demódoco ou Homero está apto a cantar pela graça da Musa ou das Musas. "Cantar", na tradição épica, significa "narrar". É indiferente se uma Musa ou muitas o inspiram, pois mesmo se as Musas (plural) estão a trabalhar, elas cantam como uma (embora alternadamente, em antifonia algumas vezes). Introduzindo Demódoco, Homero afirma, no canto 8, que a Musa "amava-o [Demódoco] acima de todos os homens" (Odisseia 8.63), e que embora ela o tivesse cegado, ela o compensaria por isso dando a ele uma "canção doce" (64). ${ }^{34}$ A habilidade de cantar (e, portanto, narrar) é aqui dita ser a compensação de um deus. ${ }^{35}$ A deficiência de Demódoco faz a enárgeia de suas canções sobre a guerra de Troia parecer um milagre. ${ }^{36}$ De fato, conforme Odisseu dirá mais tarde no mesmo livro, "a Musa ensinou fios [de narrativa] a eles [cantores] e ama o grupo de cantores" (Odisseia 8.481): ${ }^{37}$ aqui a poesia é concebida mais como a tékhne platônica, ${ }^{38}$ que é possível de ser ensinada - mas ela é "ensinada" somente a alguns a quem a Musa "ama" (i.e. privilegia) acima de outros mortais. Tal exclusividade sugere, em último caso, um "dom" divino que o cantor desenvolve através de seus esforços. ${ }^{39}$

Continuando sua chuva de cumprimentos sete linhas depois, Odisseu repete a noção de que o aedo/aoidós foi divinamente ensinado, e desta vez ele cita Apolo junto com a Musa: "Eu elogio você [Demódoco]: ou a Musa, filha de Zeus, ensinou você, ou Apolo" (Odisseia 8. 481 $)^{40}$

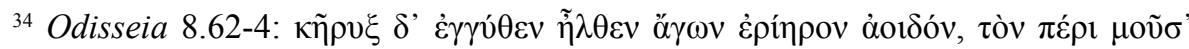

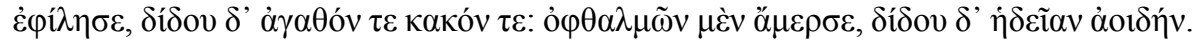
${ }^{35}$ Murray (1981, p. 89) ("nem ele [Homero] especula sobre as razões da sua concessão") deixa passar o fato de que Demódoco recebeu o dom da canção para contrabalancear a sua cegueira.

${ }^{36} \mathrm{Cf}$. a descrição do escudo de Aquiles, o qual Homero nunca viu e que inclui a cena do cerco de uma cidade (Ilíada 18.509-40). Cf. também Petropoulos (no prelo).

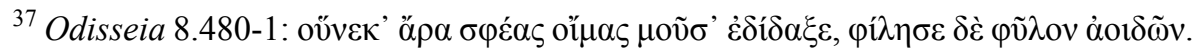
Sobre oú $\mu \eta$ cf. Nagy $(2002$, p. 72,81$)$.

${ }^{38}$ Cf., mais uma vez, Murray (1981, p. 98-99) sobre o cantor épico como um especialista

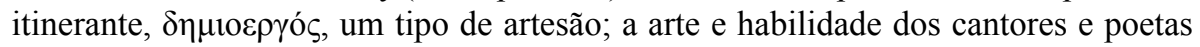

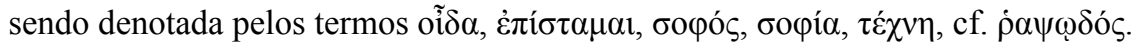

${ }^{39}$ Cf. também Murray (1981, p. 89-90; 96-97) sobre o dom da canção das Musas; e sobre a "dupla motivação" (divina e humana).

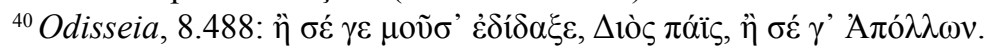


(esta é a única passagem em Homero em que Apolo é dito claramente inspirar a poesia; na Ilíada (1.604) o deus é Mousagétes, líder, ou maestro e acompanhante do coro antifônico das Musas).

A Musa fornece ao cantor épico informações todas as vezes que ele canta: "informação" - os fatos - pode soar bem banal se associada com as Musas. Mas lembremos, por exemplo, a invocação da Musa na Ilíada 1.1, e especialmente, a invocação das Musas como testemunhas da história na Ilíada 2. 484-6: "Narrem a mim agora, ó Musas, que habitam as moradas olímpicas / pois vós sois deusas e estais presentes e conheceis todas as coisas, /enquanto nós não ouvimos senão rumor e nada conhecemos." ${ }^{41}$

Homero pede para a Musa ou as Musas dizerem a ele todos os pormenores do catálogo dos navios: certamente, em segundos, elas fornecem as informações sobre os "29 contingentes conduzidos por 44 comandantes de 175 localidades gregas em 1.186 navios contendo talvez 100.000 homens" (JONES, 2003, ad loc.). Esta extrema akribología, ou "exatidão de detalhe", é possível devido às Musas que dizem exatamente o que elas viram ou ouviram na idade heroica (NAGY, 1996, p. 61). ${ }^{42}$ Os versos do poeta, além disso, contêm ipsissima verba, as mesmas palavras faladas pelos heróis e outras personagens da Ilíada e Odisseia; e "é para serem entendidos que heróis 'falavam' em hexâmetros dáctilos" (NAGY, 1996, p. 61).

De modo similar, Hesíodo é capaz de apresentar a longa, intrincada genealogia dos deuses através da ação das Musas que, como vimos, "inspiraram dentro de mim uma voz divina/maravilhosa para celebrar as coisas que serão e as coisas do passado" (Teogonia 31 ss.). ${ }^{43}$ Na mentalidade grega, movimentos e pensamentos residem nas entranhas

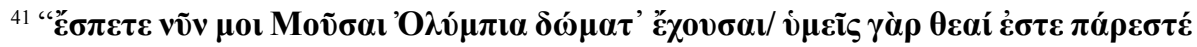

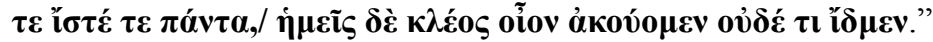

${ }^{42}$ Também Murray (1981, p. 93): “[...] na Ilíada são as Musas que veem os eventos do passado, não o bardo [...] as Musas comunicam seu conhecimento ao bardo, mas não há sugestão de que elas o fazem o transportando ao passado... o poeta é visto como estando em contato com os poderes das Musas e não como tendo esses poderes ele mesmo diretamente."

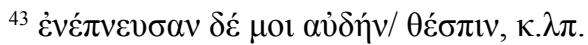


(PADEL, 1992, p. 12 ss.); assim um mortal adquire um estado de mente ou uma ideia de uma fonte externa que "sopra" a emoção ou a ideia em seu interior. Isso é, literalmente, in-spiração, દ̇ $\mu \pi v \varepsilon \tilde{v} v$ (WEST, 1966, p. 165; com bibliografia ad loc.). Mas recontar genealogias divinas envolve dificuldades de uma magnitude maior do que catalogar uma armada. É por isso que antes de mencionar esse dom da inspiração das Musas, Hesíodo cita o que as Musas declararam para ele: "Nós sabemos como proclamar ficções que se parecem com a verdade;/ nós sabemos também como declarar a verdade - quando nós desejamos fazê-lo" (Teogonia 27-8; tradução de Dover (1988)). ${ }^{44}$ Essa afirmação, que o falecido Sir Kenneth Dover caracterizou como "uma chave para a cultura grega" particularmente em respeito à abertura intelectual nas questões religiosas, é uma admissão de que muitas das coisas contadas sobre o mundo sobrenatural são verdade, mas algumas não são verdadeiras, sendo essas objeto de "preferência estética, necessidade emocional ou utilidade social” (DOVER, 1988, p. 154). A admissão de Hesíodo é um indício da originalidade grega, como também são as Musas. Como inspiradoras de poesia e música as Musas são entidades exclusivas do mundo antigo, isto é, a religião grega as inventou.

A inspiração da Musa é mais do que um mero ditado. Às Musas, o aedo (o cantor) pede que "contem" algo; o seu ato de contar faz com que ele reexperimente o que elas contam. Íon é um exemplo histriônico. Em Homero, essa reexperiência, denotada pelo verbo cognitivo

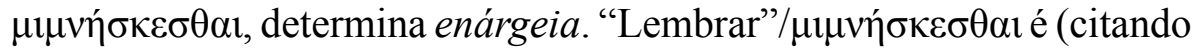
E. J. Bakker) "uma operação cognitiva dinâmica no presente" que envolve "a experiência atual de algo 'lembrado"” (BAKKER, 2005, p. 141-142); NAGY, 2013, p. 48-71). Dessa forma, um herói na Ilíada, como Aquiles, pode "lembrar" de algo de um passado recente ou distante (caso de Ilíada, 9.646-8), e, no lembrar, ele pode reagir emocionalmente e até fisicamente (BAKKER, 2005). Entretanto, pelo fato de ser o aoidós que está narrando e citando nessa narrativa, a qual as Musas lhe comunicam

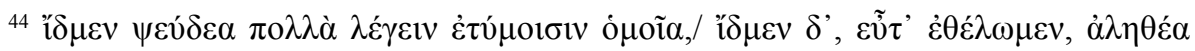

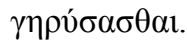


durante sua performance, é, em última instância, ele que $\mu \mu v \eta ́ \sigma \kappa \varepsilon \tau \alpha \imath$ no aqui e agora.

As Musas "ensinaram" Hesíodo, assim como elas "ensinaram" Demódoco (Teogonia 22; Odisseia 8.481). A educação pelas Musas significava que um cantor tinha acesso privilegiado a essas deusas; mas não tinha de fato a educação em suas mãos! Mousiké, o domínio das Musas, no tempo de Platão e Aristóteles, era sinônimo de educação, provavelmente porque a base da educação era a literatura (principalmente, a de Homero) e a dança, além de outros assuntos relacionados, como gramática e retórica. ${ }^{45}$ Matemática, também parte do currículo, pertencia às Musas e estava relacionada à teoria musical. No período helenístico ou mais tarde, Polímnia era também a Musa da geometria. ${ }^{46}$ Todavia, curiosamente, nunca houve uma Musa das artes visuais: nenhuma Musa inspirou os arquitetos, os pintores de vasos ou os escultores. ${ }^{47}$ Por uma série de razões, as artes visuais gozavam de um prestígio social e intelectual muito mais baixo até o final da antiguidade. Polímnia cantou Zeus e inspirou homens e mulheres a cantar e dançar, mas nem ela, nem suas irmãs inspiraram Fídias ou Escopas, os dois supremos escultores. Homero e Hesíodo pintaram imagens verbais graças às Musas, e podiam contar com sua ajuda; mas as Musas, as "cerebrais", motivaram apenas imagens mentais e não as materiais.

O Museu delas estava cheio de pinturas imaginárias, uma galeria de pinturas na mente dos poetas e nos seus espectadores. No Político o interlocutor de Sócrates diz assim: "E, todavia, é melhor representar qualquer ser vivo por discurso e argumento do que pela pintura ou qualquer arte, para pessoas que são capazes de seguir o argumento; mas para outras é melhor fazer isso por meio dos recursos de obras de artesanato" (PLATÃO, Político 277c 3-5.). ${ }^{48} \mathrm{O}$ estrangeiro considera o

\footnotetext{
${ }^{45}$ Sobre a $\mu$ ovбıкทे $\pi \alpha \iota \delta \varepsilon i ́ \alpha$ ver, ver, por exemplo, Gagarin (2013), s.v. "Education".

${ }^{46}$ Cf. CANCIK; SCHNEIDER (2006), Suppl. I, iv, s.v. "Muses".

${ }^{47}$ Kristeller (1965, p. 92) nota que "[...] foi deixado para o sofista tardio Calístrato [IV ou início do século V] para transferir o conceito de Platão da inspiração para a arte da escultura em conexão com Escopas."

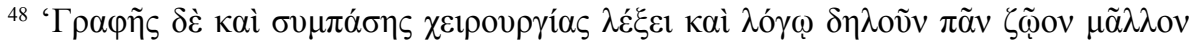

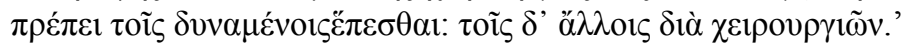


discurso superior ao desenho, provavelmente porque descrições verbais envolvem imagens mentais; enárgeia alcançada através da descrição verbal, ou léxis, é mais precisa, em último caso, do que qualquer efeito produzido por pintura material. ${ }^{49}$

\section{Referências}

BAKKER, E. J. Pointing at the Past: From Formula to Performance in Homeric Poetics. Washington, DC; Cambridge, MA: Harvard University Press, 2005.

CANCIK, H.; SCHNEIDER, H. (ed.). Brill's New Pauly: Encyclopaedia of the Ancient World. Antiquity. Leiden; Boston: Brill, 2006. v. 9 (MiniObe).

CAVARnOS, C. Plato's Theory of Fine Art. Belmont, MA: Astir Publishing Company, 1973.

CHADWICK, N. K. Poetry and Prophecy. Cambridge: Cambridge University Press, 1942.

DODDS, E. R. The Greeks and the Irrational. Berkeley: Berkeley University Press, 1951.

DOVER, K. J. The Freedom of the Intellectual in Greek Society. In: .The Greeks and Their Legacy: Prose Literature, History, Society, Transmission, Influence. Oxford: Oxford University Press, 1988. v. 2, p. 135-158.

GAGARIN, M. (ed.). The Oxford Encyclopedia of Ancient Greece and Rome. Oxford: Oxford University Press, 2013.

\footnotetext{
${ }^{49}$ Gostaria de agradecer a todas as pessoas que estiveram presentes na apresentação desse texto no Museu Mineiro, no ciclo 9+2 Musas para um Museu, por suas perguntas e comentários. Meus agradecimentos especiais principalmente à Professora Maria Cecília de Miranda Nogueira Coelho, pelo convite para apresentar, naquele ciclo, a palestra na qual este artigo foi baseado e pela tradução da mesma. Agradeço também aos Professores Pedro Ipiranga, Fernanda Lima e Celso Vieira que, generosamente, editaram versões subsequentes do texto em português.
} 
GRETHLEIN, J.; HUITINK, L. Homer's Vividness: An Enactive Approach. Journal of Hellenic Studies, Londres, v. 137, p. 67-91, 2017. DOI: https://doi.org/10.1017/S0075426917000064.

HUTCHINSON, G. O. Hellenistic Poetry. Oxford: Oxford University Press, 1988.

JONES. P. Homer's Iliad: A Commentary on Three Translations. London: Bristol Classical Press, 2003

KRISTELLER, P. O. The Modern System of the Arts. In: FEAGIN, S.; MAYNARD, P. (ed.). Aesthetics. Oxford: Oxford University Press, 1965. p. 90-102.

LIMC (Lexicon Iconographicum Mythologiae Classicae). Zurich: Artemis: Winkler Verlag, 1992. v. VII.

MURRAY, P. Plato On Poetry, Ion, Republic 376e-398b, Republic 595608b. Cambridge: Cambridge University Press, 1996.

MURRAY, P. Poetic Inspiration in Early Greece. Journal of Hellenic Studies, Londres, v. 101, p. 87-100, 1981. DOI: https://doi.org/10.2307/629846.

NAGY, G. Pindar's Homer: The Lyric Possession of an Epic Past. Baltimore; London: The Johns Hopkins University Press, 1990.

NAGY, G. Plato's Rhapsody and Homer's Music: The Poetics of the Panathenaic Festival in Classical Athens. Washington, DC; Cambridge, MA: Harvard University Press, 2002.

NAGY, G. Poetry as Performance, Homer and Beyond, Cambridge: Cambridge University Press, 1996.

NAGY, G. The Ancient Greek Hero in 24 hours. Cambridge, MA: Harvard University Press, 2013. DOI: https://doi.org/10.2307/j.ctvjghtrn.

PACHE, C. O. A moment's ornament. The poetics of Nympholepsy in Ancient Greece. Oxford: Oxford University Press, 2010. DOI: https:// doi.org/10.1093/acprof:oso/9780195339369.003.0002.

PADEL, R. In and out of the mind: Greek images of the tragic self. Princeton: Princeton University Press, 1992. DOI: https://doi. org/10.1515/9781400884322. 
RENGAKOS, A. Hesiod's narrative. In: MONTANARI, F.; RENGAKOS, A.; TSAGALIS, C. (ed). Brill's companion to Hesiod. Leiden/Boston: Brill, 2009. p. 203-218. DOI: https://doi.org/10.1163/9789047440758_009.

ROWE, C. J. Essential Hesiod: Theogony 1-232, 453-733, Works and Days 1-307. Bristol: Bristol Classical Press, 1978.

STERN-GILLET, S. Hesiod's proem and Plato's Ion. Classical Quarterly, Cambridge, v. 64, n. 1, p. 25-42, 2014. DOI: https://doi.org/10.1017/ S0009838813000517.

WEST, M. L. Hesiod Theogony. Edited with prolegomena and commentary. Oxford: Oxford University Press, 1966.

WEST, M. L. Hesiod Works \& Days. Edited with prolegomena and commentary. Oxford: Oxford University Press, 1978.

Recebido em: 10 de novembro de 2018. Aprovado em: 5 de março de 2019. 